$\begin{array}{r}\text { Volume and Issues Obtainable at Center for Sustainability Research and Consultancy } \\ \text { Journal of Accounting and Finance in Emerging Economies } \\ \text { ISSN: 2519-0318 \& ISSN (E): 2518-8488 } \\ \text { Volume 7: Issue 3 September 2021 } \\ \text { JSRᄃ } \\ \text { Journal homepage: } \text { www.publishing.globalcsrc.org/jafee } \\ \hline\end{array}$

\title{
Impact Factors on Internal Audit Quality of Businesses the Case Study of Karachi Pakistan
}

*Muhammad Abdullah Idrees, KASB Institute of Technology, Karachi, Pakistan Ayesha Khan, Bahria University, Karachi, Pakistan

Insiya Abbas, Bahria University, Karachi, Pakistan

Muhammad Bilal, Indus University, Karachi, Pakistan

*Corresponding author's email address: idrees@kasbit.edu.pk

\begin{tabular}{l}
\hline ARTICLE DETAILS \\
\hline History \\
Revised format: Aug 2021 \\
Available Online: Sep 2021
\end{tabular}

Keywords

Internal Audit Quality,

Auditors, Auditing,

Management, Audit Firms

JEL Classification

M42

\section{OPEN ACCESS}

\section{ABSTRACT}

Purpose: Internal Audit Quality is relied upon to prompt top notch financial reporting to the outsiders of the businesses. Excellent financial reporting communicates in earning quality. Earning quality has been playing a key role in the capital market for quite a while. Account clients give exceptional consideration to procuring quality since they settle on their choice dependent on it. Then again, the market economy will encounter terrible, gone misfortunes if the association's exhibition isn't reflected in its income.

Methodology: This examination targets researching the connection between Internal Audit Quality, a leading group of audit quality and financial reporting. Exploration information, acquired from 300 audit firms had internal audit offices. Just the selected firms met inclusion standards, to which research polls were sent. At long last, 300 surveys were affirmed as satisfactory, and were taken as exploration test.

Findings: Discoveries indicated that excellent Internal Audit Quality will prompt great financial reporting. Additionally, solid top managerial staff will fortify this connection.

Implications/Originality/Value: So, it is concluded that all these three newspapers were mostly against the peace talks and government and media were not on the same page on the issue of peace talks. (Times New Roman 11pt including headings and text, single line spaced).

(C) 2021 The authors, under a Creative Commons Attribution-

NonCommercial- 4.0

Recommended citation: Idrees, M. A., Khan, A., Abbas, I. and Bilal, M. (2021). Impact Factors on Internal Audit Quality of Businesses the Case Study of Karachi Pakistan. Sustainable Business and Society in Emerging Economies, 7 (3), 697-716.

\section{Introduction}

\section{Background}

The dissertation has provided perceptions keen on the efficiency of Internal Auditing (IA) that is observed as an unexplored 'black box' in academic research. That subject matter is a sort of 'Elephant in the room', that is, an obvious issue no one or only a few want/s to discuss. This examination starts to 
make up for the shortfall by considering the adequacy of the Internal Audit.

To guide the informed and uninformed reader on the subject matter of my dissertation, I first Define what constitutes IA effectiveness and explain the importance of the topic. I reference the gap in academic literature and how this dissertation contributes to knowledge. I disclose my particular motivation to carry out this research before detailing the multi-method and multi-perspective approach chosen in the study to provide fresh insights into this field (Lenz \& Rainer, 2020).

The researchers' investigations have suggestions for the viability of inward review from the viewpoint of correspondence of the danger alerts. It isn't our mean to give a formula to the inside inspector on the best way to augment IA adequacy, however, we give a few proposals to an inward review that could emphatically add to the IA viability.

A chief demonstration that isn't eager to tune in to the danger notice message that the continuation of a data framework project isn't sensible and the undertaking should be diverted or ended. The Manager demonstrations in the part of a review (the board) that isn't happy to tune in to the danger notice message identified with the dangers engaged with the executives' dynamic in the association all in all. The courier, giving the danger admonitions our examination is the inner reviewer who is a sound source that makes genuine affirmations dependent on an intensive examination incongruity with the inside inspecting principles and prerequisites (Centre, 2018).

The authors of the Institute of Internal Auditors (IIA), featured the requirement for an inner review work as "need made inward inspecting and is making it an essential piece of present-day business. No huge business can get away from it. On the off chance that they haven't got it now, they should have it eventually, and, if occasions, creating as they do as of now, they should have it sooner (Obeid, 2007).

The new corporate disappointments have expanded the conspicuousness of interior evaluating. Concerning the issue, the creator has contended that the insolvencies, monetary abnormalities, and deceitful exercises that happened at Enron, WorldCom, and different firms have expanded the requirement for corporate checking. He inferred that outer review disappointments identified with these occasions' increments the job of inner evaluating incorporate checking (Obeid, 2007).

Associations have experienced quick changes in monetary multifaceted nature, extended administrative prerequisites, and mechanical headways as of late. Notwithstanding these progressions the current corporate outrages and the worldwide monetary emergency likewise pushed people in general and administrative bodies to give the exceptional situation to inward review in corporate administrations interior affirmation administration (Berehe, 2016).

The development of inside review as an order is followed to the mid-1940s when the Institute of Internal Auditors (IIA) was set up in 1941 at Lake Mary, Florida, USA. The primary book on interior inspecting, Modern Internal is examining, was additionally distributed. Therefore, the inside review calling has been becoming worldwide under the worldwide administration of the Institute of Internal Auditors (IIA) (Berehe, 2016).

A basic condition for the endurance of an organization or all the more and large of an association lies in the capacity of its individuals to act dependably and effectively to accomplish the goals of the association. The generous coordination of conduct can be accomplished from various perspectives. In a private company, the supervisor can confirm straightforwardly that the undertakings have acted in the manner he believes is appropriate. Be that as it may, the oversight of the chief and the common change among different creators are rapidly getting inadequate when the number of firms expanded. In any case, it very well might be wished to keep up these methods of controlling however; it would simply be applied to the piece of the association. In this way, it is vital that the administration set up systems to fill 
the hole in management (Saud and Marchand, 2012).

Great administration turned into a profoundly effective business issue toward the start of the $21 \mathrm{st}$ century, following a progression of huge corporate embarrassments and disappointments. Great administration alludes to government organizations' lead in executing creative arrangements and projects to expand the nature of public help with a definitive point of expanding financial development Such imaginative approaches and projects address administration viewpoints, for example, straightforwardness, responsibility, interest, and polished methodology. Great administration prompts great administration, great stewardship of public cash, great public commitment, and eventually, great results for residents and administration clients. Great administration empowers a position to seek after it vision successfully just as supporting that vision component for the administration of danger as referenced by OECD in 2004 (Unam and Asaolu, 2016).

The viability of the control climate, add esteem and improve an association's operations the internal audit, these objectives can be achieved and the activities also be designed to assess these objectives. Internal audit assesses the suitability of the internal system and controls if finds hazards then endorse to improve these controls (Unam \& Asaolu, 2016).

\section{Problem Statement}

The previous works have tried to find out the Internal Audit functions are related to the experience of external audit in this regard the framework worked surrounding of legality, decentralizing and stakeholders' theories and reported to the government agencies with the effective financial statement. The effective internal audits prevent non-compliance with the laws, rules and regulations. The good governance can be prevailed within the system through internal control. The internal controls provide better monitoring of the organization and its feedback on the system which have been well defined (Gabrini, 2013).

In the USA the new, New York Stock Exchange, corporate administration guidelines require each recorded organization to keep an inner review work, while in the UK the new Combined Code didn't need UK recorded organizations to have an inside review work, yet organizations ought to legitimize their choice not to have an interior review work. Sudan was colonized by Britain and influenced by the British monetary Laws and guidelines. All things considered, the Sudanese Companies Act doesn't need recorded or unlisted organizations to build up an inside review work yet the bank of Sudan guidelines requires each bank working in Sudan to set up an interior review office and require each bank to introduce inspected accounts with a greatest time of 3 months after the conclusion of.

As inward and outer evaluators are worried about the strength of interior review work and both are endeavoring to keep up the connection between the two capacities, the issue Selected for in this investigation is intrinsic in addressing the accompanying inquiries:

1. How the segment foundation of inner and outside inspectors impacts them Assessment of inner review work in Sudanese banks as far as, objectivity, Capability and work execution and observing of interior controls?

2. To what degree the outside reviewers answerable for banks' reviews are depending on the Work of inner examiners in Sudanese banks, corresponding to, objectivity, capability also, work execution and observing of inward controls kept up by inner Review offices? (Obeid, 2007).

In this study paper, it is to be examined that the effective internal audit provides such impact that create not only better governance by the management, but also satisfied the external audit authority and government agencies by fulfilling the legality, decentralizing and stakeholders' theories with the reporting of the effective financial statement. It is also examined that the non-compliance of the audit laws, rules and regulations can be controlled through the internal controlling system which provides immediate feedback if any hazard finds to show the good governance by the management to prove its 
effectiveness internal control.

\section{Research Gap}

The previous studies have provided the details of the elements that are considered to be affected on the adequacy Internal Audit as concentrated by the written literature. The literature acknowledges that a powerful Internal Audit brings incentive to the association by guaranteeing the adherence to the set-up strategies, laws, and guidelines, and give occasion to improve existing cycles. Be that as it may, the current partners additionally pinpoint a broadening gap between the desires for Internal Audit stakeholders. Appropriately, the fundamental issues are frequently recognized after the Internal Audits, which cause a trouble in deciding if the review was compelling or not. Besides, it was recommended that evaluating the adequacy of Internal Audit may be provided by analyzing the variables that may impact the adequacy of Internal Audit. In this manner, it is Important to examine these variables and address our subsequent exploration question.

This study paper considers the examination as an extensive source that offers pointers on the variables explored in the literature and a reason for future exploration in this field to address the gap that are identified. The commitments of this examination will help in better understanding the state of the exploration on interior review viability, including the compelling components, and gapes open doors for future exploration.

\section{Research Objectives}

The principal point of this investigation is to inspect the strength of inner review work in Sudanese banks and in this manner to assess the dependence put by outer evaluators on Crafted by inner evaluators. To accomplish this primary point, the accompanying targets were set for the investigation:

1. To take the perspectives on members (interior and outer evaluators) with respect to:

a. Focus on the objectivity of inner review offices at Audit firms, Companies, and Businesses.

b. Proficiency of inner review offices at Audit firms, Companies, and Businesses.

c. Performance and observing of inner controls at Audit firms, Companies and Organizations

2. To analyze the job of segment factors (schooling, experience, insight into inner examining, the quantities of inside evaluators in the interior review offices, inspectors' occupation, examiners' area, and sex) according to their assessments of:

a. Focus on the objectivity of interior review divisions at Audit firms, Companies and Organizations

b. Proficiency of inward review offices at Audit firms, Companies, and Businesses

c. Performance and checking of interior controls at Audit firms, Companies, and Businesses

3. To survey the level of outer inspectors on crafting by interior examiners in Audit firms, Companies, and Businesses thinking about the reviewers' area (private review firms and the General Auditors).

4. To clear the distinction in the inspecting writing as for the investigation factors,

5. Providing recommendations for overseeing objectivity, ability, and work execution and checking of inside controls, in view of the examination results for the Audit firms, Companies, and Business area in Pakistan (Karachi). 


\section{Research Questions}

The following main hypotheses were proposed by the theoretical framework and tested in the course of this study:

1. How does the Performance of Auditors have an impact on Internal Audit Quality.?

2. How does the Management Support have an impact on Internal Audit Quality?

3. How does the Autonomy to Implement audit Technique have an impact on Internal Audit Quality?

4. How do the Physical Environment, Health and Safety have an impact on Internal Audit Quality?

5. How do the Promotion and Reward have an impact on Internal Audit Quality?

6. How do the Training and Development have an impact on Internal Audit Quality?

7. How does the Audit budget have an impact on Internal Audit Quality?

\section{Literature Review \\ Internal Audit}

In this examination paper, the first concerning the assessment of inside review work in the Audit firms, Companies, and Business areas in Pakistan essentially in Karachi. Where, the agricultural nations are in more prominent need of comparable examinations to assist them with creating and increment their insight in the zone of inward inspecting and the connection among inner and outer evaluators.

Secondly, this examination could be valuable to scholars and specialists. For the scholars, it will improve their comprehension of the variables that fortify the inside review work, in particular objectivity, skill, and work execution and observing of inner controls and outside the reviewers' trust in crafting by inward inspectors. For professionals, it might assist with taking care of the reasonable issues confronting the interior review capacity of Pakistan's business areas regarding its objectivity and fitness and its connection among inside and outside evaluators.

Thirdly, in Pakistan, rarely to utilize more than one exploration strategy. This research study applies triangulation examination strategies by brushing the poll review, for inspecting the investigation factors across an enormous number of cases, with the Meeting strategy, the components influencing the strength of interior review work. This blend may give a superior clarification of the examination issue, which is the primary driver for picking the suitable exploration techniques (Gabrini, 2013).

\section{Internal Audit Quality}

Internal audit quality expects examiners to do their job and in consistence with acknowledged measures for proficient practice, with the end goal that inside review movement will assess and add to the improvement of danger the executives, control and administration utilizing an orderly and trained methodology The Institute of Internal Auditors (IIA). This is significant for consistence with legitimate necessities, but since the extent of an evaluator's obligation could include the assessment of regions in which an elevated level of judgment is included, and review reports may directly affect the choices or the strategy received by the executives (Lenz \& Rainer, 2020).

The more prominent nature of IA work - comprehended regarding consistence with formal norms, just as a significant level of productivity in the review's arranging and execution - will improve the review's adequacy. Nonetheless, the IIA requests consistence with its Code of Ethics, which demands that inside reviewers will perform interior review administrations as per the International Standards for the Professional Practice of Internal Auditing and will constantly improve their capability and the adequacy and nature of their administrations (Unam \& Asaolu, 2016).

\section{Organizations}

In outcomes the authoritative status of the inside review division, seen that the autonomy of the interior review office is controlled by the way in which it is directed. In accordance with characterized the hierarchical autonomy as the circumstance that will permit the interior review movement to satisfy its 
capacity with adequacy (Saud \& Marchand, 2012).

It has contended that the supervisory crew's help is central and that the head of interior inspecting ought to have direct access and the opportunity to answer each Supervisor including the leader, chief, the top chief, and the review council (Gabrini, 2013).

\section{Internal Audit Management and Department}

It has been discovered that focused on that the overseer of the inward review Office in organizations is answerable for the consistence of inward review the standard confirmation adequacy and ability. The inner review office representatives size rely on the exercises of the association as it has four degrees of expert inspectors: chiefs, administrators, ranking staff (Asaolu and Unam, 2016).

\section{Employees}

Coming up next are the duties of the inside review office's workforce: The overseer of inward evaluating: is answerable for the general interior inspecting Capacity. His duties incorporate arranging, gives examining approaches and Methodology, overseeing staff, coordination of work with outer examiners and the Association with the governing body and review board and sets up a review Quality program.

The inner review supervisor: is answerable for directing individual reviews, other than arranging and planning the review work. Chiefs ought to have a sensible administrative experience. Ranking staff, inspectors have the obligation to manage the review work; ranking staff generally have the insight of three years in the field of evaluating. Junior staff examiners: generally, do, the not so much perplexing, but rather more day by day and routine work (Centre, 2018).

\section{Internal Audit Reporting Level}

The freedom of the inside review office should be created and maintained all through the whole pecking order of the association. It tends to contend that, the level to which the division reports can be a marker of its autonomy and position in the association.

For instance, the head of the inside review division ought not to be responsible to the leader answerable for money (boss bookkeeper or account chief) since this will bargain the evaluator's autonomy.

As proposed by the Statement of Auditing Standards, SAS No SAS 65, the hierarchical freedom of inner review staff is basic for their objectivity.

Nonetheless, while thinking about the objectivity of inward examiners, the other reviewer ought to perceive the authoritative level to which inward reviewers report their outcomes what's more, in this way, the authoritative level to which they report officially. This can be a pointer of the degree of their capacity to act autonomously of the people answerable for the capacity being reviewed (Saud \& Marchand, 2012).

\section{Governments}

As more prominent accentuation is currently being laid on acceptable administration and responsibility, Internal Control expects a lot more noteworthy significance, and should be planned in a more present day and logical way to guarantee the validity and proficiency. The principal capacity of all branches of the Federal Board of Revenue is to guarantee the assortment of due income, for the Federal Government, and to check its spillage through avoidance. A powerful Internal Control, through Internal Audit, subsequently has an immediate bearing on income. In the event that it positively affects income assortment, it will be seen as being valuable and viable. The Directorate General, Internal Audit (Indirect Taxes) whose primary errand is Internal Control, through Internal Audit, Investigative review and watchfulness, has this fundamental target in view. In any event, when Audits are led for guaranteeing right use of law, techniques, rules and guidelines, the fundamental thought is to help secure 
authentic income (Saud \& Marchand, 2012).

\section{Performance of Auditors}

The independence of internal auditor is considered as a critical driver for Internal Audit adequacy. In this substance, the independence is characterized as "the independence from conditions that undermine the capacity of the Internal Auditor movement to complete Internal Audit duties in an unprejudiced way". To permit the inner evaluator direct Internal Auditor freely, there ought to protect instruments in the Internal Auditor division. The investigation uncovers that the reference archive that contains the function of the Internal Auditor's office in the association, its privileges of admittance to people, records and resources, and the report sets out the extent of inner examining are gainful to guarantee Internal Auditor freedom. The writing concurs that the absence of freedom is a snag to good Internal Auditor execution (Özkan \& Turetken, 2019).

\section{Management Support}

Despite the fact that Internal Auditor can have an enormous level of independence and self-governance, they may even now have a restricted ability to play out their obligations inside an association. Thus, the management support gets basic to encourage the inside evaluators in directing their obligations. Like the case in any considerable endeavor in an association, the help and support of the top management for Internal Auditing play a significant job, especially in the usage of the audit recommendations [S1], [S13], [S16]. Along these lines, a few examinations consider the management support as a significant impacting factor on the Internal Auditing viability. These examinations (e.g., [S1] and [S13]) normally utilize a bunch of survey things to catch representatives' observation with respect to the level of the management support for IAs (Gabrini, 2013).

\section{Autonomy to Implement audit Technique}

The associations have a bit of the issues range from insufficient dispersions, limited wellsprings of pay, inadequacies, feeble inside control system, and survey methodology occurring to spillages and distortion. Meanwhile, the premise of the regional government Association, a game plan of changes has happened with the purposes of ensuring its objectives of groundbreaking and capable utilization of resources. Inward survey unit being a basic segment of the record structure of the local government should be coordinated with all the basic resources and support for its convincing limit. A steady complaint in the zone by the general populace exceptionally the occupants of the areas are closer to close by power is that the unit which is set up to check the budgetary dealings of the close by government (internal survey unit) is unreasonably weak in its abilities either due to lacking staffing, delicate internal control, vulnerable association, nonattendance of required labor force, inadequate documentation, and usage of fitting inside audit methods in the local governments, among others, to prevent distortion (Onoja Emmanuel E, 2015).

\section{Physical Environment, Health and Safety}

The climate where the heads perceive the importance of controls and the structures that overview their sufficiency can empower the correspondence with various laborers, who consistently consider a to be audit as an 'association police', and better appreciation of within the survey work of the board. The control climate suggests the plan standards, cycles, and structures that give the reason of making internal authority over the affiliation. It concerns the respectability and moral estimations of the association, the administrative structure and duties, the cycle for pulling in, creating, and holding equipped people, and the thoroughness around execution measures, motivating forces, and compensations drive responsibility for execution. The investigation in [S19] reports a critical relationship between the nature of IA and the control environment part of the inward control framework. Additionally, the concentrate in [S34] contends on the positive impact of the steady control environment on the IA viability. The elements that depict the strong control environment are frequently utilizing proclamations starting from the COSO system 2013. Such proclamations mean to catch discernments on the explanations that speak to specific parts of the control environment, for example, the moral mindfulness and the executives' style, the 
degree of mindfulness for the significance of control, and the presence of big business management risk and related checking exercises (Ö̈zkan \& Turetken, 2019).

\section{Promotion and Reward}

Internal auditors may have various thought processes (monetary awards from supervisors, individual associations with chiefs to act against the governing body interest, and its review advisory group. To play out an inward review action expertly and impeccably, they should be able to make all around defending decisions, future situating of interior examiners and their compensations, instruction and expert confirmation, and involvement with leading a review. Furthermore, the presence of a powerful review council with an outright expert in the association has settled the above issues (Wodajo, 2019).

\section{Training and Development}

The nature of internal Audit work will play critical positive effect on internal Audit adequacy since when administrators and clients segment accepted on the nature of internal Audit, they will see audit work in as a key point for association this will expands the help given by managers to build the measure of spending plan appointed to internal Audit and expert staffs training given to engage internal Audit staffs, last this activity will improve Internal Auditors viability. Subsequently, review quality has a huge and constructive outcome on inward review viability (Berehe, 2016).

Organization's management has a close relationship with internal auditors in their day-to-day activities. They need good support and the perception of their management to be more effective and develop audit technique to achieve the audit objectives. Management support is expressed in terms of supporting the auditing process by fulfilling the necessary resources, finance, transport if required, providing training, introducing auditors with new technology and procedures, budgeting funds for certification other facilities that facilitate the internal auditing works. Management support has a far-reaching consequence on IA effectiveness in organizations (Wodajo, 2019).

\section{Audit, Budget}

Inward review offices in Sudanese banks are likewise influenced by these issues in terms of budgetary requirements that have restricted the assets designated for inward review offices. Along these lines, financial plans dispensed for preparing of inner review staff were diminished. The exploration members believed interior review offices to be fundamentally understaffed and once in a while can't cover the banks' exercises in a fitting manner (Obeid, 2007). 


\section{Conceptual Framework}



\section{Research Methodology}

\section{Method of Data Collection}

The personnel who relate to the auditing department are approached by interviewer for taking interview or management of auditing or any other related person who has the knowledge of the Internal Auditing or persons are related to finance department and know the accounting basics. The primary data collection is adopted

The close ended questionnaire is prepared with the different options consists of the research topic as shown in the appendix I and the approached to the related personnel who know or are currently working in Audit Departments or in any way are getting in touch with the Internal Audit. The Likert Scaling adaptive questions adopted.

\section{Theoretical Model}

As shown in the literature, all the investigation factors relate together into a hypothetical model as laid out in conceptual framework. The Concept of this piece of study is presentation of theory dependent on inspecting writing to explore the impact of Internal Audit the enormous business to searching for auditing departments or organizations. The resulting objective is improvement of theoretical models to overview the impact of internal audit at enterprises (Obeid, 2007).

This study paper has recognized both dependent and independent factors. The free factors are all of those internal auditing services that are given by auditors to its clients. In this way, the finding of the assessment study depends upon the relationship and yields of ward and independent factors. The 
schematic theoretical structure shows the association between dependent and independent factors in literature review.

\section{Role and Responsibility of Internal Auditor}

The fundamental occupation of inside assessment is to help the heads with achieving authoritative goals. It similarly gives certification that the organization has executed a satisfactory inside control system to prevent possibilities. Additionally, assessing should give inside directing organizations at all levels of the affiliation with respect to planning, advice, help, and course (IIA, 2011). The Institute of Internal Monitors gave the internal assessing obligations; the part related to objections communicated, "The objective of inward-looking at is to help all people from the chiefs in the fruitful arrival of their obligations by furnishing them with examinations, assessments, proposition, and proper comments concerning the activities reviewed. The inside inspector is stressed over any time of a business development where he can be of an organization to the board. This incorporates going past accounting and money related records to gain a full understanding of the exercises under study.

It was also portrayed advantages of inner inspecting help, which gives activity and judgment premise to administrators by detailing, execution and interior control impediments and suggestions for enhancements, for arrangement of business issues giving insight to governing body and administrators for its arrangement and giving valuable, convenient and solid data to the administration.

Moreover, the assertion additionally specifies the inner inspector administrations types and exercises kind accomplishing the general targets. The inner inspector evaluates the firm tasks as arranged and to decide the results with the set-up targets and assesses the inward control framework sufficiency and adequacy of the organization. The fundamental reason to check the sufficiency of the inward evaluating of the organization is to decide about the sensible confirmation arrangement that the organization targets met efficiently (Saud \& Marchand, 2012).

\section{Data Analysis and Interpretations \\ Descriptive Analysis}

The phenomenological worldview is portrayed to be a subjective technique that burdens the emotional parts of human movement that centers on the importance as opposed to estimation of common spectacles. That is offered that this methodology depicted as the descriptive strategy and specifies that each occasion should be concentrated in a one-of-a-kind occurrence in its own right.

\section{Multiple Regression Analysis}

Multiple linear is an all-inclusive type of basic straight relapse. It is used when we need to envision the assessment of a variable subject to the assessment of at any rate two distinct factors freely. The variable we need to predict is known as the needy variable. The components we are using to anticipate the assessment of the destitute change are known as the autonomous variable. (Ali, 2019)

The reliability test is tested first on the data collected after that the multiple linear regression as a model is run to check the influence of the independent variables on the dependent variable.

In this study paper the hypothesis regarding the influence of the 1-Performance of Audit, 2- Top Management Support, 3-Autonomy to Implement audit Technique, 4-Physical Environment, 5Promotion and Reward, 6-Training and Development, 7-Availability of the Budget on the Internal Audit Quality which identify the strength and weaknesses of internal Audit Quality finding the appropriate results in long- term objectives. To simplify the model and easy to predict each variable item has been transformed into average (mean). Then the model runs in SPSS to check the hypotheses. 


\section{Multiple Linear Regression Models}

The model for MLR, given in observations, is:

$\mathrm{Y} i=\mathrm{B} 0+\mathrm{iB} 1 \mathrm{x} 1+\mathrm{B} 2 \times 2 \mathrm{i}+\ldots+\mathrm{Bpxp}+\mathrm{E}$

Where,

$\mathrm{Y}=$ Dependent Variable

$\mathrm{X}=$ Independent Variable

$\beta=$ Beta Coefficient

According to this research

$\mathrm{Y}=\beta 0+\beta 1 \mathrm{X} 1+\beta 2 \mathrm{X} 2+\beta 3 \mathrm{X} 3+\beta 4 \mathrm{X} 4+\beta 5 \mathrm{X} 5+\beta 6 \mathrm{X} 6+\beta 7 \mathrm{X} 7+\mathrm{Ei}$

$Y=$ Internal Audit Quality

$\mathrm{X} 1=$ Performance of Audit

X2= Top Management Support

$\mathrm{X} 3=$ Autonomy to Implement audit Technique

$\mathrm{X} 4=$ Physical Environment

$\mathrm{X} 5=$ Promotion and Reward technical support

X6= Training and Development

$\mathrm{X} 7=$ Availability of the Budget

Internal Audit Quality = B0+ B1 Performance of Audit + B2 Top Management Support + B3 Autonomy to Implement audit Technique + B4 Physical Environment + B5 Promotion and Reward + Technical support $+\mathrm{B} 6$ Training and Development $+\mathrm{B} 7$ Availability of the Budget

\section{Validity and Reliability}

The reliability assessment is the underlying stage in the quality control of leading examination, contingent upon the essential information assortment. The dependability examination frameworks process different generally used proportions of scale, dependability, quality, and moreover give information about the associations between particular things in the scale. Association coefficients can be used to measure cover rate steadfast quality evaluations. In this manner, by using faithful quality, insightful, how much the things in the survey are related to each other can be settled, so we can get an overall record of the dependability or within the consistency of the scale as a total. Using the unwavering quality examination can perceive issues things that should be evaded from the scale. In this assessment, Cronbach's Alpha was used, considering its congruity an overview relies upon the Likert five-point scale, and measures within the consistency of the survey, taking into account the typical between the relationships of the things (Obeid, 2007).

\section{Outcomes and Analysis of the Results}

\section{Dependent and Independent Variables Cronbach Alpha Analysis}

Table 1.1: Showing the Cronbach's Alpha $(\alpha)$ Statistical Reliability test

\begin{tabular}{l|l}
\hline \multicolumn{2}{l}{ Reliability Statistics } \\
\hline Cronbach Alpha & No of Items \\
\hline 0.896 & 48 \\
\hline
\end{tabular}

In this table it depicts that the reliability test which shows that the all 48 items can be taken all to gather for testing. As the alpha value $(\alpha=0.896)$ of Cronbach provides relief to instrument to collect the data from the instrument. 


\section{Descriptive Statistics Mean and Standard Deviation Dependent Variable (Internal Audit Quality) with different Dimensions}

\begin{tabular}{|c|c|c|}
\hline Variable & & \\
\hline References & Mean & Deviation \\
\hline Dependent Variable & & \\
\hline $\begin{array}{l}\text { Does the existing role that internal auditors play sufficient to IAQ1 } \\
\text { address the purpose for which it is established? }\end{array}$ & 2.08 & .998 \\
\hline $\begin{array}{l}\text { Does the organization internal audit ensure activity performed is IAQ2 } \\
\text { compliance with established policies, procedure, laws and } \\
\text { regulations? }\end{array}$ & 3.06 & .905 \\
\hline $\begin{array}{l}\text { Does the internal audit activity influence positive change and IAQ3 } \\
\text { continual improvement of business processes, bottom line results } \\
\text { and accountability within the organization? }\end{array}$ & 2.08 & .998 \\
\hline $\begin{array}{l}\text { Does the internal activity, promote appropriate ethics and values IAQ4 } \\
\text { within the organization? }\end{array}$ & 2.86 & 1.079 \\
\hline $\begin{array}{l}\text { Do the Organization Internal Audit findings \& recommendations IAQ5 } \\
\text { critical and Constructive to improve non-compliances activities or } \\
\text { control systems of the organization? }\end{array}$ & 2.60 & 1.041 \\
\hline
\end{tabular}

$\begin{array}{llll}\text { Does the non-compliance report provide internal audit is reliable IAQ6 } & 2.58 & .983\end{array}$

and significant to the organization?

Do the number of complaints (doubts) about the internal audit IAQ7

2.32

1.049

finding (report) represent very low because the report is correct and

reasonable?

Does the internal audit ensure the economical, effective and IAQ8

3.30

.923

efficient use of the organizational resources?

Do inter auditors of the organizational capable of carrying out the IAQ9

2.14

1.022

internal control function under current corporate governance?

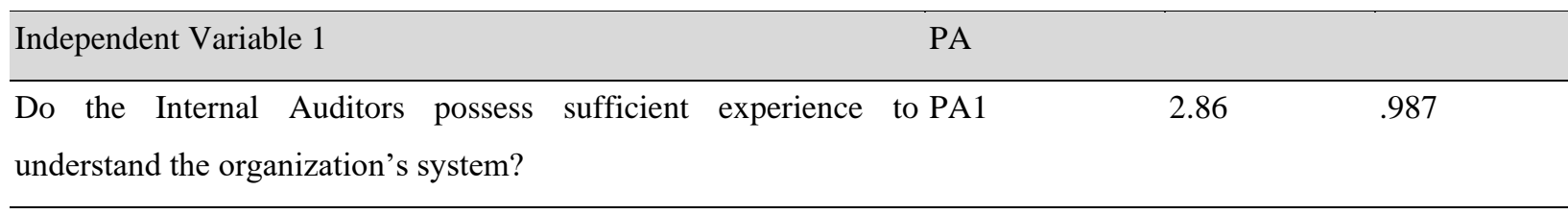

Do the Internal Audit staffs have the appropriate and relevant PA2

2.40

1.079

education in auditing that allow them to audit all of the

organization's systems (financial, operational, logistical and computerized).

Do Internal Auditors undertake continuous professional PA3

2.94

.975

development activities (such as professional association sponsored

programs and correspondence courses)? 
Do the Internal Audit staff number and their skill match the scope PA4

of organizational internal, operations?

Does the work of Internal Audit is performed with modern PA5

2.86

1.081

technology that is used computerized data tools and specific IA

software?

Independent Variable 2 MS

Does the top level management trust and value the advice of the MS1

2.60

1.041

internal audit?

Does the Internal Audit service see as a key strategic partner MS2

2.86

.982

throughout the organization?

Do the senior managers understand and fully support the work of MS3

2.40

1.079

internal audit?

Do Internal Auditors have full access to records and information MS4

2.94

.969

they need?

Does Internal Audit obtain a sufficient budget to carry out its duties MS5

successfully?

Independent Variable 3

AIT

Have you freely decided the scope, time and extent of auditing AIT1

2.08

.998

procedures based on auditing standards and the organization

policy?

Does the internal auditing operate totally independently; any issue AIT2

3.10

.856

in the audit can be considered for auditing?

Do you perform the auditing activities without any interference AIT3

2.08

.998

from anybody and without any influence from the organization?

.Does the Internal Audit staff have free access to information and AIT4

2.08

.998

data about the organization, and unrestricted access to its site?

Does the organization encourage me to implement my AIT5

2.86

1.079

recommendations, to promote value-added activities and strength

internal audit function?

Independent Variable 4

EHS

Does the organization develop Environment, Health and safety plan EHS1

2.08

.998

strategy?

\begin{tabular}{llcc}
\hline Does the organization provide Medical services? & EHS2 & 3.10 & .856 \\
\hline Does the management provide a hygienic environment? & EHS3 & 2.08 & .998 \\
\hline Does the Implement environmental Management? & EHS4 & 2.32 & 1.049 \\
\hline Monitor and manage operational environmental aspects? & EHS5 & 3.30 & .923
\end{tabular}


Does the Implement environmental Management Manage EHS6

Corporate Environmental Data?

\begin{tabular}{llcc}
\hline Does the Organization Plan \& Manage Emergency Response? & EHS7 & 2.86 & .982 \\
\hline $\begin{array}{l}\text { Does the Organization provide Incident Learning and Prevention? } \\
\text { EHS8 }\end{array}$ & 2.40 & 1.079 \\
\hline $\begin{array}{l}\text { Does the Organization manage legal requirement and commitments EHS9 } \\
\text { and Identify, evaluate and action regulatory changes? }\end{array}$ & & 2.94 & .969
\end{tabular}

\begin{tabular}{|c|c|c|c|}
\hline Independent Variable 5 & PR & & \\
\hline Is the linguistic and cultural diversity hurdle in working? & PR1 & 2.86 & .982 \\
\hline Is the benefit important part of the total remuneration Package? & PR2 & 2.83 & 1.118 \\
\hline $\begin{array}{l}\text { Does the earnings of the Internal Auditors are related } \\
\text { performance? }\end{array}$ & PR3 & 2.91 & .993 \\
\hline
\end{tabular}

Do the remuneration policies, identify the long term results than PR4

short term ones?

Does the remuneration system in the organization is futuristic PR5

3.31

1.058

orientation. It focuses auditor's attention on long term goals?

Independent Variable 6 TD

Does the management prepare well in technical knowledge to enter TD1

3.26

1.272

the workforce, which they also regarded as more important overall

than "soft skills"?

Does the internal auditor expect of the management to assume a TD2

2.83

1.191

large portion of the responsibility of preparing him/her for a new

position after training?

Does the organization provide training to deliver the technical TD3

2.73

.957

knowledge with workshops, courses by the firms associated with

on-the-job training?

Does the technical training have more important than formal TD4

3.00

.900

training?

Does the training that Internal Auditors currently receive seems to TD5

2.69

.873

meet or exceed their perceived need for formal training?

Does the clear training and development have an important TD6

3.11

.915

consideration to most internal auditors in planning their career

progression?

Does the internal auditor express concern that there are gaps in TD7

3.09

1.024

their receiving the appropriate training?

Independent Variable $7 \quad$ AB

Does Internal audit obtain a sufficient budget to successfully carry AB1 out its Duties? 


\begin{tabular}{lcc} 
Do Auditors review checking of budget implementation? & AB2 & 2.93 \\
\hline Does the firm set the actual time and budget for key performance AB3 & 1.81 & .799 \\
and audit assignment? & \\
\hline
\end{tabular}

Number of Cases 300

\section{Mean of Elements of Dependent Variable}

Having a glance at this table the highest mean of Internal Audit Quality8 (IAQ8) which is (mean=3.30) that relates to the dependent variable. It means that it is the most controlled determinant of dependent variable while the second highest mean of IAQ2 which is (mean=3.06) and it secondly well controlled determinant of the dependent variable. The lowest mean of the dependent variable element is 2.08 IAQ1. It means this determinant need to control more as it's far from other elements.

\section{Mean of Elements of Independent Variables}

The lowest mean of the independent variable element is $1.81 \mathrm{AB} 3$. It means this determinant need to control more as it's far away from other elements of independent variables.

The highest mean of the element of the independent variables is 3.31 PR5 and TD5 3.26 which are controlled by the firms, but may not remain the same in the next academic research.

\section{Standard Deviation of Elements of Dependent Variable}

The highest deviated element is IAQ4 $(\mathrm{SD}=1.079)$. It means that it is far from the its mean and out of control and the management of the audit firms need to control it, but the determinants do not remain the constant forever they change over the time. The next academic research may find this element in a different way or closer to its mean.

The lowest Standard deviation is $(\mathrm{SD}=0.905)$ of $\mathrm{IAQ} 2$ which is the closest to its mean and the audit firms do not need to more focus on it but over the time it may change in the future.

\section{Standard Deviation of Elements of Independent Variable}

The highest deviated element is $\mathrm{AB} 2(\mathrm{SD}=1.214)$ It means that it is far away from the its mean and out of control and the management of the audit firms need to control it but the factors do not remain the same forever they change over the time. The next academic research may find this element in a different way or closer to its mean.

The lowest Standard deviation is $\mathrm{AB} 3(\mathrm{SD}=0.799)$ which is closer to its mean and the audit firms do not need to more focus on it but over the time it may change in the future.

\section{Hypotheses Assessment Summary}

Table 4.3: Depicts the model summary explain the independent Variances to the dependent Variable

Model Summary

\begin{tabular}{lllll}
\hline Model & $\mathrm{R}$ & R Square & $\begin{array}{l}\text { Adjusted } \\
\text { Square }\end{array}$ & $\begin{array}{c}\text { R Std. Error of the } \\
\text { Estimate }\end{array}$ \\
\hline 1 & $.965^{\mathrm{a}}$ & .931 & .929 & .152
\end{tabular}


Model Summary

\begin{tabular}{lllll}
\hline & & & Adjusted & R Std. Error of the \\
Model & $\mathrm{R}$ & R Square & Square & Estimate \\
\hline 1 & $.965^{\mathrm{a}}$ & .931 & .929 & .152 \\
\hline
\end{tabular}

a. Predictors: (Constant), Audit budget (AB), Physical Environment

Helath And Safety(EHS), Training And Development (TD),

Autonomy To Implement Of Audit Technique(AIT), Promotion And

Reward(PR),Management Support (MS), Performance Of Auditor

(PA)

In this table it depicts that dependent variable Internal Audit Quality variance is explained 96.5 percent by the seven independent variables Audit Beudget (AB), Physical Environment Helath And Safety (EHS), Training And Development (TD), Autonomy To Implement Of Audit Technique(AIT), Promotion And Reward(PR),Management Support (MS), Performance Of Auditor (PA) as shown by the $\mathrm{R} 2$ value. It means that these independent variables are directly correlated with the dependent variable

Table 4.4: Showing the beta coefficient of Independent variables and their Impact on Dependent Variable.

\begin{tabular}{|c|c|c|c|c|c|}
\hline \multirow[b]{3}{*}{ Model } & \multirow{2}{*}{\multicolumn{2}{|c|}{$\begin{array}{l}\text { Unstandardized } \\
\text { Coefficients }\end{array}$}} & \multirow{3}{*}{$\begin{array}{l}\text { Standardized } \\
\text { Coefficients } \\
\text { Beta }\end{array}$} & \multirow[b]{3}{*}{$\mathrm{t}$} & \multirow[b]{3}{*}{ Sig. } \\
\hline & & & & & \\
\hline & $\mathrm{B}$ & Std. Error & & & \\
\hline (Constant) & .094 & .069 & & 1.360 & .175 \\
\hline Performance Of Auditor (PA) & -.869 & .057 & -.717 & -15.202 & .000 \\
\hline Management Support $\quad(\mathrm{MS})$ & .552 & .046 & .462 & 12.046 & .000 \\
\hline $\begin{array}{ccc}\text { Autonomy } & \text { to } & \text { Implement Of } \\
\text { Technique } & \text { (AIT) } & \end{array}$ & .406 & .014 & .612 & 29.064 & .000 \\
\hline $\begin{array}{l}\text { Physical Environment, Health and Safety } \\
\text { (EHS) }\end{array}$ & .859 & .033 & .756 & 26.402 & .000 \\
\hline Promotion And Reward (PR) & -.039 & .019 & -.049 & -2.086 & .038 \\
\hline Training And Development (TD) & .029 & .019 & .028 & 1.511 & .132 \\
\hline Audit Beudget & .026 & .018 & .032 & 1.467 & .144 \\
\hline
\end{tabular}

a. Dependent Variable: Internal Audit Quality

\section{Hypotheses testing}

\section{Performance of Auditor}

H1: How does the predictor (Performance of an auditor) have an impact on (Internal Audit Quality)? There is a connection between the size of the interior review quality and review firm. Experience of the Internal Audit and Firm Performance The third assessment of IAC is the knowledge of inside survey. Exactly when an individual has various significant stretches of inclusion, he/she can make a right decision, pick brisk and deal with any condition. This variable is assessed by the amount of years the people have gathered through an overview that is dispatched off each firm by email Reliable with the asset reliance hypothesis and its advocates, master people help in firm development since they have a reasonable knowledge about how to manage measure and achieve their undertakings prevalent quality. 
Furthermore, when the firm gives board high specialists, they help to comprehend outer climate and thus, will improve execution of organization there is a relationship between the size of the internal audit and firm performance (Al-Matari, Al-Swidi, \& Binti Fadzil, 2014).

This study paper has also found that Performance of Auditor (PA) has a negative effect as its beta coefficient is (- 0.869) it is significant as its probe value is $<0.05(0.000)$. It means that the Performance of Auditor (PA) has significant impact on the dependent variable Internal Audit Quality (IAQ) but it is not necessary that it will remain the same in the future. This independent variable may get better and positive significance effect in future research.

\section{Management Support (MS)}

H2: How does the predictor (Management Support) have an impact on (Internal Audit Quality)?

As demonstrated by the awesome interchanges these organization instruments look like a corporate organization mosaic. In any case, issues among free and boss bosses in light of disproportion information shows inside survey more likely as a correlative instrument. This is maintained by choosing affirmations from investigates breaking down the association between survey sheets and inside audit.

This is according to the IIA see about inside analyzing; which urges relationship to improve and survey organization measures. Thusly, positive connection between the Internal Audit Quality and a more grounded review panel can be typical due to their solidly destinations. A practical audit leading body of trustees can fortify the internal survey work position; however, an earth-shattering internal survey limit can achieve improved the audit warning gathering's stability (Saud \& Marchand, 2012).

This study paper has also found Management Support (MS) has a positive effect as its beta coefficient is (0.552) it is significant as its probe value is < 0.05 (0.000). It means that the Management Support (MS) has a significant positive influence on the dependent variable Internal Audit Quality (IAQ). The more will be the experience management support the better will be the results of the audit but it is not necessary. This independent variable opens new ways of thinking in the future.

\section{Autonomy to Implement of Audit Technique (AIT)}

H3: How does the predictor (Autonomy to Implement Of Audit Technique) have an impact on (Internal Audit Quality)?

It has been discovered that there is the huge connection between inward review procedure and customary interior evaluating approach in misrepresentation anticipation at the neighborhood government by the Pearson Product Moment Correlation Coefficient test on the huge connection between inner review method and conventional inside inspecting approach in blackmail evasion at the close by government. The r-decided is 0.72 which is a colossal difference with r-essential found to be 0.28. It appropriately dismisses the invalid hypothesis that state, there is no tremendous association between inside survey technique and standard inward reviewing approach in coercion expectation at the close by the government. Thusly, enduring the political race hypothesis that state, there is a basic association between inward audit system and traditional examining approach in deception evasion of the local government.

This study paper has also found Autonomy to Implement Of Audit Technique (AIT) has a positive effect as its beta coefficient is (0.406) it is significant as its probe value is $<0.05(0.000)$. It means that the Autonomy to Implement of Audit Technique (AIT) has significant positive Impact on the dependent variable Internal Audit Quality (IAQ). When the audit technique is implemented for the internal audit the results will be better. 


\section{Physical Environment, Health and Safety (EHS)}

H4: How does the predictor (Physical Environment, Health and Safety) have an impact on (Internal Audit Quality)?

The administration and overseers of an element receive the cycle of inside a control. This cycle gives affirmation about the achievement of the substance's objectives as for financial uncovering, exercises, and reliability with the rules. External is looking at the rules and shows that the controlled atmosphere can be sustained by using fruitful in survey work by:

1. Review of the inward control structure of a firm.

2. For the administration; checking various tasks as to data framework and control techniques. Interior Health, Safety, Environment, and Quality (HSEQ) Audit Programs can be improved with a portion of the accompanying things:

3. A persistently improving HSEQ the board framework structure that encourages the distinguishing proof of the dangers, openings, and steady controls.

4. Strong administration that sees HSEQ execution greatness as one of the keys to in general corporate execution?

5. Productive checking and self-appraisal programs by bleeding edge and specialty unit danger and control proprietors with driving execution measurements that drive wanted results.

6. An autonomous interior review work with spending plan, staff, and skill equivalent with the nature and profundity of HSEQ danger and control development.

7. Contribution of outside specialists where validity and mastery are required.

8. Great information investigation and computerization.

9. Danger based review program plan that centers on basic controls, and business measures. 1

10. Vigorous episode investigation and analysis of the causes and holes distinguished during the review.

11. Describing review outcomes elder management and the board of full straightforwardness.

12. Communication, constant improvement theory. (Brun, 2018)

This study paper has also found Physical Environment, Health and Safety (EHS) has a positive effect as its beta coefficient is (0.859) it is significant as its probe value is $<0.05(0.000)$. It means that the Physical Environment, Health and Safety (EHS) have significant positive impact on the dependent variable Internal Audit Quality (IAQ). The more will be the better environment for health and safety the management work provides good results.

\section{Promotion and Reward (PR)}

H5: How does the predictor Promotion and Reward (PR) have impact on (Internal Audit Quality)?

To see the impact of the board uphold on the interior review adequacy a relapse investigation was done and its yield shows a beta estimation $\beta=0.299, \mathrm{P}<0.05$; from this figure we can presume that the inside review viability is straightforward and altogether affected by the help the review group got from the administration. Thusly, invalid theory H30 (There is no certain connection between top administration upholds and interior review adequacy) is rejected. This outcome was steady with the past inspecting research works of .They have found that the top administration upholds was the basic determinants of inner review adequacy. The ministration shapes the association vital move and in the event that they consider being an essential point for the association they will give all the vital contribution to the fruitful (Berehe, 2016).

This study paper has also found Promotion and Reward (PR) has a negative impact as its beta coefficient is $(-0.039)$ it is significant as its probe value is $<0.05(0.000)$. It means that the Promotion and Reward (PR) has significant negative impact on the dependent variable Internal Audit Quality (IAQ). This will unfold to think the management in the future academic research because the factors never remain the same forever. 


\section{Training and Development (TD)}

H6: How does the predictor Training and Development (TD) have an impact on (Internal Audit Quality)?

Inter Audit dependent on preparing prerequisites hypothesized by the Institute of Internal Auditors (IIA) that requires rehearsing CIAs (Certified Internal Auditors) to have on normal 40 hours out each time of proceeding with proficient instruction (CPE). Among others, agrees with this view and finishes up 'the best inner review capacities. It has worked with are constantly seeming to be imaginative and improve the manner in which they work. As the IA movement doesn't add to administration in a similar way as it does to controls (IIARF 2011b, 5) potentially in light of the fact that these review subjects are seen as especially requesting, sufficient preparing to perform administration, misrepresentation and moral reviews can be useful and may build the opportunity that interior inspectors convey more and better.

In this study paper, it has been found that the Training and Development (TD) has not significant impact on the Internal Audit Quality (IAQ) because its probe value is $>0.005$ that is $(0.132)$. This factor may change in the future of academic research and gives better results.

\section{Audit Budget (AB)}

H7: How does the predictor Audit Budget (AB) have an impact on (Internal Audit Quality)?

The best five devices utilized by and by (IIARF, 2009: 12) when self-observing IA execution is consistent with the review plan (i.e., the quantity of reviews arranged versus the number executed); consistent with a financial plan; a fulfillment overview from audit; review time the board (arranging, hands on work, shutting); and revealing time the management.

In this study paper, it has been investigated that the Audit Budget $(A B)$ does not have significant influence of the Internal Audit Quality (IAQ) its probe value if greater than $>0.005$ that is 0.144 . This factor has found insignificant not forever, it may be changed in the future academic research. When internal audit practices will change by using the new techniques, training and development by providing new education regarding accounts as the market regarding finance is changing rapidly as the time passing.

This study paper has found most of the independent variables significant, but two of them are the insignificant.

\section{Discussion and Conclusion \\ Discussion}

The earlier study over the internal audit quality, providing has been conducted since 2014 and the auditing specialists trying to figure out that in reality the audit quality is provided or not and still established that this not providing properly. Much of the earlier research has found that the chances have been disappeared to build better audit quality. The internal audit quality is the most effective tools to provide long lasting benefits as well as multiple returns on investment within a short period (months) by hiring and retain the average audit experts this is the question that is still alarming in audit and finance department (Berehe, 2016).

In this paper, it has been trying to figure out the factors which make it easier to deliver the internal audit quality process which not only help the public but also the private sectors to fetch out the experts which make internal audit quality more and more outclass, flexible and adaptable.

\section{Conclusion}

The internal audit and audit organizations, both together can provide much better benefits not only 
domestically but also globally. Internal Audit Quality helps the auditors to polish in the tasks and provides grip to face new challenges whatever they are and whenever they arise. The Internal Audit Quality process can find out the management who works effectively and efficiently, which not only cut down the cost of organizations but also provides satisfaction to the clients.

\section{References}

Ali, M. G. (2019). Access To Finance And Smes Growth In Emerging Econoies: Moderating Role Of Financial Literacy (A Comperative Study Of Manufacturing And Service Sector). National University Of Modern Languages, Islamabad.

Al-Matari, E. M., Al-Swidi, A. K., \& Binti Fadzil, F. H. (2014). The Effect Of The Internal Audit And Firm Performance: A Proposed Research Framework. International Review Of Management And Marketing, 1-8.

Asaolu, T., \& Unam, M. J. (2016). Promoting Good Governance Through Internal Audit Function (Iaf): The Nigerian Experience. International Business Research, 196.

Berehe, F. A. (2016). Determinants Of Internal Audit Effectiveness In Roads Construction Sector, Case Study In Ethiopian Roads. St. Mary's University School Of Graduate Studies.

Brun, J. W. (2018). Internal Audit Best Practices For Environment, Safety,Risk, And Quality. 1-19.

Centre, E. M. (2018). Effectiveness Of Internal Audit .

Coulson-Thomas, C. (2012). Talent Management And Building High Performance Organisations. European Journal Of Training And Development, 43, 266-274.

Gabrini, C. J. (2013). The Effect Of Internal Audit On Governance:Maintaining Legitimacy Of Local Government. Florida State University Libraries, 197.

Karthick, R. (2018). A Study On The Implementation Of Green Supply Chain- A Comparative Analysis Between Small Scale Industries In India And Developed Nations. Mälardalen University.

Lenz, \& Rainer. (2020). Insights Into The Effectiveness Of Internal Audit. Digital Access Ton Liabraries.

Naeem, A. (2013). The Impacts Of Micro-Finance On Enterprise, Households \& Entrepreneur In Quetta, Pakistan . Department Of Public Administration, Gomal University, Dera Ismail Khan.

Obeid, O. A. (2007). Evaluating The Strength Of The Internal Audit Function: The Case Of Sudanese Banks. Liverpool Jhon University .

Onoja Emmanuel E, P. (2015). Internal Audit Techniques And Fraud Prevention: A Case Study Of Selected Local Government Councils In Bauch State. Mediterranean Journal Of Social Sciences Mcser Publishing, Rome-Italy, 4, 232.

Özkan, B., \& Turetken, O. (2019, October ). Internal Audit Effectiveness: Operationalization And Influencing Factors. Managerial Auditing Journal.

Saud, S., \& Marchand, N. (2012). Contribution Of Internal Audit In The Achievement Of Corporate Goals. Karlstad Business School Handelshagskolan Vid Karlstad Univerties.

Unam, M. J., \& Asaolu, T. (2016). Promoting Good Governance Through Internal Audit Function (Iaf): The Nigerian Experience. International Business Research.

Wodajo, A. (2019). Factors Affecting Internal Audit Effectiveness: The Case Of Ethiopian Insurance Companies. College Of Business And Economics.

Statistics-Reliability. (2014, April). Retrieved From Www.Explorable.Com/Statistical-Reliability: Https://Explorable.Com/Statistical-Reliability 